\title{
Endoscopic diverticulotomy by harmonic scalpel (Ultracision): an experimental model
}
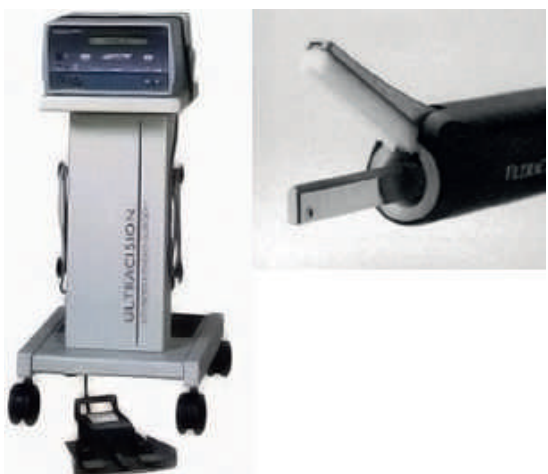

Fig. 1 Harmonic scalpel and the Ultracision generator.

Treatment of Zenker's diverticulum by flexible endoscopy is considered to be feasible and safe [1]. Bleeding and perforation remain the main complications of endoscopic incision of Zenker's diverticulum [2]. The harmonic scalpel (Ultracision) ( $\bullet$ Fig. 1) has been employed in laparoscopic surgery [3] and provides adequate and accurate hemostasis. The concept of a harmonic scalpel involves coaptive coagulation in which vessels are tamponaded and sealed by a protein coagulum or desiccated tissue, or both. Coagulation with the ultrasonically activated scalpel blade is always coaptive, and vessels are sealed by a denatured protein coagulum [3].

This report describes the use of a harmonic scalpel to perform flexible endoscopic diverticulectomy in an acute porcine model. A soft diverticuloscope [4] (ZD overtube, ZDO-22-30; Wilson-Cook, Winston-Salem, North Carolina, USA) ( $\bullet$ Fig. 2) was employed to provide better exposure of the septum and protection of the anterior esophageal and posterior diverticular walls [5], allowing the passage of the harmonic scalpel (Ultracision ACE36P; Ethicon Endo-Surgery, Inc., Cincinnati, Ohio, USA). Under endoscopic vision (GIF-145, Olympus, Tokyo, Japan) the soft diverticuloscope was brought into position to expose the diverticular bridge. Then, the harmonic scalpel was introduced through the diverticuloscope under endoscopic assistance, which permitted cutting of the diverticular septum up to the fundus of the diverticular sac without bleeding or any sign of perforation

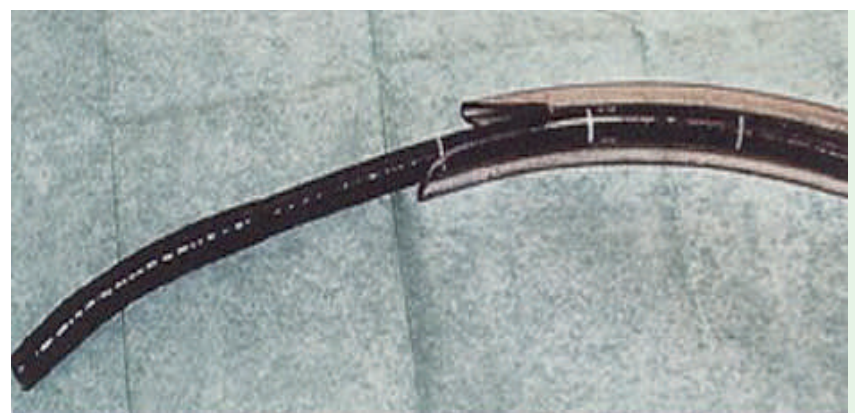

Fig. 2 Soft diverticuloscope (ZD overtube)
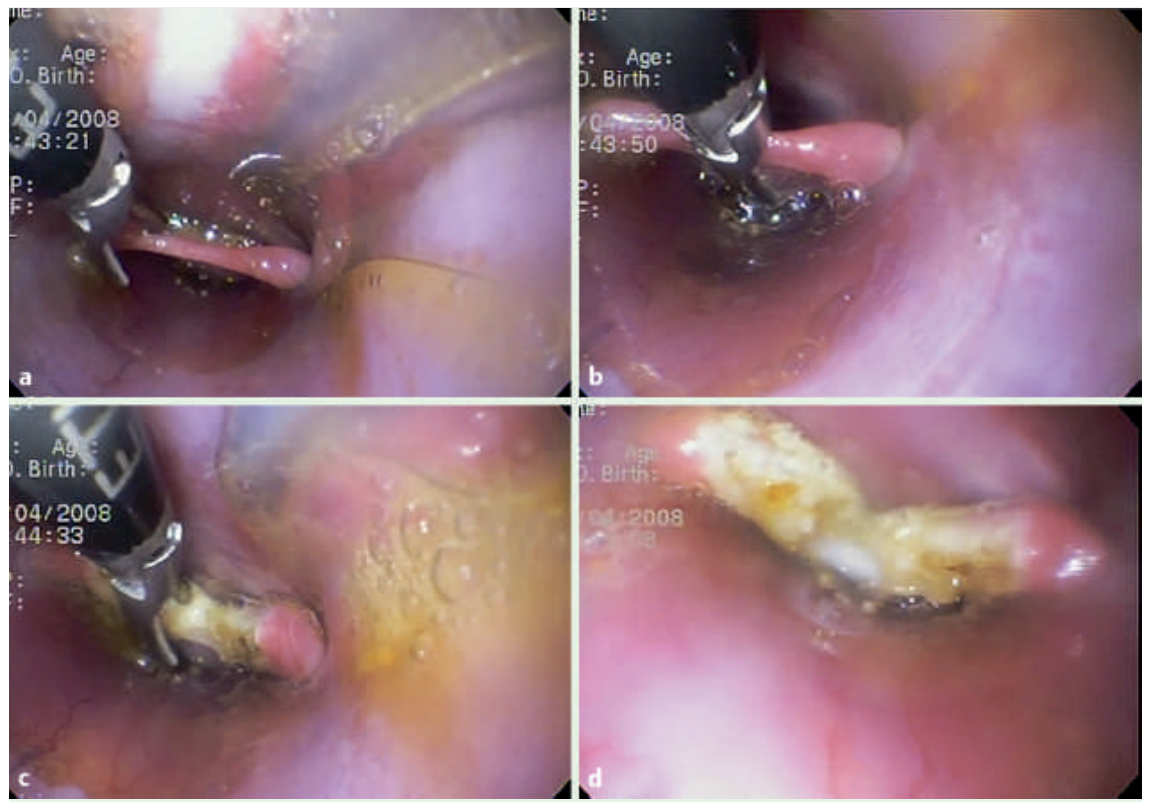

Fig. 3 Endoscopic view of the procedure. a Harmonic scalpel being brought into position. $\mathbf{b}$ Harmonic scalpel starting to cut. c Continuous cutting of the diverticular septum. $\mathbf{d}$ Final aspect.

(๑ Fig. 3). The animal was euthanized and the operated portion was resected and inspected for any evidence of perforation ( $\bullet$ Fig. 4).

The harmonic scalpel has been already demonstrated to be a better hemostatic tool than monopolar or bipolar electrocoagulation, and also results in less tissue damage [3]. It seems to be useful in patients with coagulation disorder. Further studies will be necessary to confirm the efficacy and safety of harmonic scalpel for the endoscopic treatment of Zenker's diverticulum.

\section{Endoscopy_UCTN_Code_TTT_1AO_2AD}

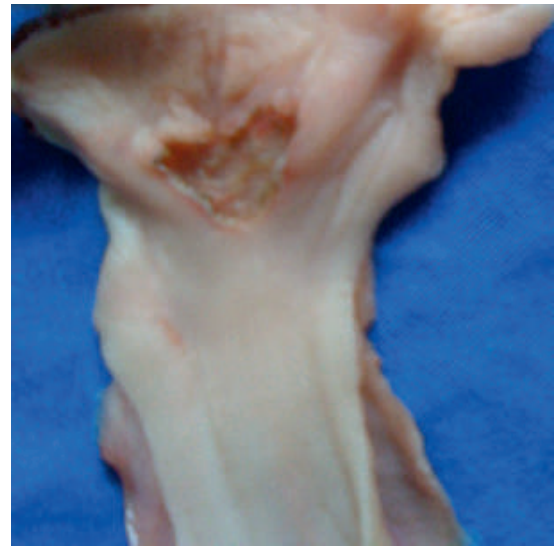

Fig. 4 Resected specimen showing, through the anterior esophageal wall, the diverticular septum cut up to the fundus of the diverticular sac. 
F. Y. Hondo ${ }^{1}$, F. Maluf-Filho' ${ }^{1}$, J. H. Giordano-Nappi' ${ }^{2}$, R. J. Duarte'2, R. Kuga',

E. Grecco ${ }^{1}$, M. Srougi ${ }^{2}$, P. Sakai ${ }^{1}$

${ }^{1}$ Gastrointestinal Endoscopy Unit, Hospital Clinics of University of São Paulo Medical School, São Paulo, Brazil

2 CEPEC - Experimental Surgery Laboratory, University of São Paulo Medical School, São Paulo, Brazil

\section{References}

1 Ishioka S, Sakai P, Maluf-Filho F et al. Endoscopic incision of Zenker's diverticula. Endoscopy 1995; 27: 433-437

2 Ferreira LEVVC, Simmons DT, Baron TH. Zenker's diverticula: pathophysiology, clinical presentation, and flexible endoscopic management. Dis Esophagus 2008; $21: 1-8$

3 Diamantis T, Kontos $M$, Arvelakis $A$ et al. Comparison of monopolar electrocoagulation, bipolar electrocagulation, Ultracision, and Ligasure. Surg Today 2006; 36: 908 913

4 Evrard S, Le Moine O, Hassid S et al. Zenker's diverticulum: a new endoscopic treatment with a soft diverticuloscope. Gastrointest Endosc 2003; 58: $116-120$

5 Costamagna G, Iacopini F, Tringali $A$ et al. Flexible endoscopic Zenker's diverticulotomy: cap-assisted technique vs. diverticuloscope-assisted technique. Endoscopy 2007; 39: $146-152$
Bibliography

DOI 10.1055/s-0028-1119605

Endoscopy 2009; 41: E104-E105

(c) Georg Thieme Verlag KG Stuttgart · New York . ISSN 0013-726X

\section{Corresponding author}

\section{F. Y. Hondo}

Gastrointestinal Endoscopy Unit, Hospital Clinics of University of São Paulo Medical School

R. Panamericana, 64

São Judas

São Paulo-SP

Brazil 04303-170

fyhondo@uol.com.br 